\title{
APPLICATION OF REMOTE SENSING, GIS, AND GPS TECHNOLOGY ON ENVIRONMENT AND EARTH'S NATURAL RESOURCES MANAGEMENT AN INTRODUCTION
}

N. Nandini, ${ }^{*}$ Aboud S. Jumbe, ${ }^{* *}$ Sucharita Tandon ${ }^{* * *} \&$ Sunita N. ${ }^{* * * *}$

\begin{abstract}
Remote sensing data have been used to derive thematic information of various natural resources and environment. The type and level of information extracted depends on the expertise of the analyst and what $s /$ he is looking for in the data. An application in remote sensing is the practical use to which a series of aerial satellite images are put. The application of remote sensing or Earth observation techniques to atmospheric, Earth and environmental sciences can vary according to the final user's requirements. The utilization of remote sensing dato
\end{abstract}

Reader and Chairperson, Department of Environmental Science, Bangalore University, Inanabharathi Campus, Bangalore 560056, Email: Nandini.sai@rediffmail.com

** Ph.D Scholar, Department of Environmental Science, Bangalore University Inanabharathi Campus, Bangalore 560056,Email: aboud.jumbe@gmail.com

*** Ph.D Scholor \& Guest Faculty, Department of Environmental Science, Bangalore University, Jnanabharathi Campus, Bangalore 560056,Email: sucharito_aprl1@yahoo.com

**** Lecturer, Department of Environmental Science, Bangalore University Inanabharathi Campus, Bangalore 560056 
can be broadly classified into three categories as a baseline data generator for a variety of environmental resources; as a tool to monitor change detection, Environmental monitoring, and for mapping purposes. Different environmental applications require different frequencies of information updates for monitoring to be effective. Environmental phenomena such as weather systems, natural hazards, and other rarely extreme events such as tsunamis; pollution or oceanographic events are very dynamic and rapidly develop over minutes and hours. Therefore for satellite data to be useful in their analysis imaging frequency and data delivery has to be at least several times a day. At present only low spatial resolution meteorological satellite data can meet this need. Other applications such as crop monitoring require better spatial detail but rates of change occur only over a matter of weeks and therefore image updates need not be more frequent than weekly or monthly. This data can be processed, refined, and managed with the use of advanced tools such as Geographic Information System (GIS) and Geographic Positioning System (GPS)

\section{Introduction}

Remote sensing data have been used to derive thematic information of various natural resources and environment. The type and level of information extracted depends on the expertise of the analyst and what s/he is looking for in the data. An application in remote sensing is the practical use to which a series of aerial satellite images are put. The application of remote sensing or Earth observation techniques to atmospheric, Earth and environmental sciences can vary according to the final user's requirements. The utilization of remote sensing data can be broadly classified into three categories as a baseline data generator for a variety of environmental resources; as a tool to monitor change detection, Environmental monitoring, and for mapping purposes.

Environmental monitoring, in contrast to environmental assessment, is concerned with not just a static assessment or observation of an environmental parameter at one point in time. Rather it means being able to update information and observations of these parameters regularly in order to monitor dynamic processes. Therefore environmental monitoring requires a regular supply of data on the environmental parameters being observed/assessed. The first application in environmental monitoring was in the field of the meteorology and weather forecasting. 
Different environmental applications require different frequencies of information updates for monitoring to be effective. Environmental phenomena such as weather systems, natural hazards, and other rarely extreme events such as tsunamis; pollution or oceanographic events are very dynamic and rapidly develop over minutes and hours. Therefore for satellite data to be useful in their analysis imaging frequency and data delivery has to be at least several times a day. At present only low spatial resolution meteorological satellite data can meet this need. Other applications such as crop monitoring require better spatial detail but rates of change occur only over a matter of weeks and therefore image updates need not be more frequent than weekly or monthly.

\section{Satellite Data Sources for Environmental Monitoring}

The key satellite and sensor systems used for environmental monitoring are the meteorological satellites GOES (including meteosats) and NOAA AVHRR as these satellites produce daily imagery of most of the earth's surface. These satellites are used because of the frequent data collection, the size of the area that is imaged, and because their imagery is available free to anyone with a suitable satellite receiver. Some environmental phenomena do not need such frequent updates of imagery but do need more spatial detail in order to be assessed. Therefore LANDSAT Thematic Mapper, Landsat MSS and SPOT Multispectral (XS) data can also be used for environmental monitoring. Since many environmental phenomena are likely to occur beneath cloud cover or at night, radar imageries such as that obtained from ERS or RadarSat can often provide invaluable data. This will become increasingly useful as scientists better understand the interpretation of radar data.

\section{Application of Remote Sensing in Meteorology and Weather Forecasting}

Meteorology and Climatology are considered first as they can be fundamental to understanding other environmental parameters. Many monitoring application have been developed by the use of meteorological satellites measurement of the rainfall regimes in an environment in order to assess the status of vegetation/ crops, risk of drought, bush fires, or insect infestations. Assessment of the weather is fundamental to the welfare of the human population worldwide. Rainfall is the most variable meteorological parameter and is the key limiting factor to crop and rangeland production. In excess, it can also have a devastating effect such 
as floods and soil erosion. Increasingly, therefore, dense and accurate rainfall observation is required to meet the needs of growing human populations and their demand on marginal lands.

However over the last two decades the availability and reliability of rainfall data from convectional rain gauge networks particularly in tropical and subtropical regions have declined. In addition, rain gauge data sets report at point location and do not provide a spatially continuous record of rainfall. Large areas of the world are devoid of rain gauges particularly in remote areas and spatial interpolation is difficult. Even where spatial interpolation can be performed, spatial and temporal variability of rainfall can give rise to serious errors of overgeneralization.

Meteorological satellite data provide wide area continuous coverage at frequent enough intervals 30 minutes to every 6 hours to enable rainfall monitoring or at least rain cloud assessment in areas deficient of rain gauge cover. Satellite rainfall estimates complement rain gauge measurements by giving a better idea of the spatial distribution and variability of rainfall and by filing the gaps between rain gauge locations.

Satellite data can provide information on cloud cover and rainfall in the visible, thermal infrared, and microwave regions of the spectrum. The early techniques used visible and infrared imagery analysis. But recent research is now developing reliable technique for monitoring rainfall form passive and active microwave data. None of the techniques give direct measurements of rainfall. Estimations are derived from either cloud mapping or analysis (nephanalysis) or in the case of microwave instruments, by electromagnetic radiation waves having physical interaction with the rain droplets (scattering effect).

\section{Application of Remote Sensing in Vegetation Monitoring}

Much of the Earth's land surface has an uppermost cover of vegetation which intercepts electromagnetic radiation transmitted through the atmosphere. As a consequence, satellite images obtained over land surface invariably contain areas of vegetation cover. Remote sensing is important in the following areas such in natural vegetation resource inventory; land cover assessment. - Mapping and Monitoring; monitoring planted crops; detection of diseased and insect infested crops, etc. 
The electromagnetic response from vegetated surfaces is fundamentally based on the spectral response of a leaf structure. The outer layer of the leaf is composed of the cuticle and epidermis and specialized translucent cells which can be penetrated by electromagnetic radiation. The lower layer of the leaf comprises of stomatal pores. The palisade cells are beneath the upper epidermis and contain chloroplasts with chlorophyll, a pigment that absorbs the blue and red element of the white light but reflects the greener elements. Therefore healthy vegetation appears green in the visible range and it is this layer of cells that is responsible for most of the reponse from the leaf in the visible part of the spectrum. A leaf reflects about $10-30 \%$ of total light falling on it in the green part of the spectrum.

The sponge mesophyll cells are irregularly shaped cells with a large surface area. These cells reflect about $60 \%$ of the near infra-red irradiation back form the leaf. The internal structure of the leaves plays a key role in the bright near infra red response of the living vegetation, the peak reflectance of vegetation being in the near infra red, not green part of electromagnetic spectrum. Therefore the near infrared bands of the satellite and airborne imagery are very useful in vegetation discrimination. The response in the near infrared enables separation of vegetation from non-vegetated surface which are usually darker in the NearIR. Differences in reflectivity of plant species are more pronounced in the Near IR than in the Visible Green; the discrimination of different vegetation types is thus often better in the near IR than in the Visible. However it is useful to take note of the Earth's surface response in the Visible red too. As a high response in both the visible red and Near IR indicated that the surface is not vegetated but likely to be an artificial anthropogenic surface.

As a plant senesces or becomes distressed or diseased, cells die. They change in structure and lose their chlorophyll pigment. The spectral characteristics of the leaf therefore changes and that is why it is useful to and detecting and mapping th aerial extent of vegetation deterioration that is due ti disease, insect infestation. The Near Ir $\mathrm{c}$ an also be used to detect the natural senescence associated with ripening crops. At longer IR wavelengths greater than 1.3 Micrometers, the water content controls the spectral response of a leaf. Longer wavelength radiation between 1.4 and 2.5 micrometers is absorbed by the leaf.

\section{Vegetation Indices (VI)}

Vegetation indices are empirical formulae designed to emphasize the spectral contrast between the Red and Near IR region of the Electromagnetic spectrum that is around 0.7 micrometers. They produce digital quantitative measures which 
attempt to measure Biomass and vegetative health; the higher the VI value, the higher the probability that the corresponding area in the ground hectare dense coverage of a healthy green vegetation. They can be regarded as a more sophisticated form of the ratio of the Near IR and Red Bands of the spectrum. Moreover, a vegetation index can also be regarded as mechanism by which image band data can be combine to compressed form (by reducing the relevant Red and near IR band information in to a single band image) so that future processing, classification, becomes more efficient.

In the course of time, several different vegetation indices have been developed. They include Perpendicular Vegetation Index (PVI); Normalized Different Vegetation Index (NDVI); Difference Vegetation Index (DVI); Weighted Difference Vegetation Index (WDVI); Soil Adjusted Vegetation Index (SAVI); Transformed Soil Adjusted Vegetation Index (TSAVI); Ratio vegetation Index (RVI); Modified Soil Adjusted vegetation Index (MSAVI); Global Environment Monitoring Index (GEMI). These indices are subject to more elaborate and further studies.

\section{Application of Remote Sensing and Land Use/ Land Cover}

Land cover is the physical material at the surface of the earth. Land covers include vegetation, water, mountains, deserts, etc. There are two primary methods for capturing information on land cover: field survey and through analysis of remotely sensed imagery. Land cover is distinct from land use despite the two terms often being used interchangeably. Land use is a description of how people utilize the land and socio-economic activity - urban and agricultural land uses are two of the most commonly recognized high-level classes of use. At any one point or place, there may be multiple and alternate land uses, the specification of which may have a great dimension.

Land use is the activity for which land is used. Patterns of land use arise naturally in a culture through customs and practices; but land use may also be formally regulated by land use planning through zoning and planning permission laws, or by private agreements such as restrictive covenants. Land use planning encompasses the following disciplines: Architecture; Environmental planning; Landscape architecture; Regional Planning; Spatial planning; Sustainable Development; Transportation Planning; Urban design; Urban planning; Urban Renaissance; and Urban renewal.

Architecture, urban design, urban planning, landscape archifecture and urban renewal usually address the selection of physical layout, scale of development, 
aesthetics, costs of alternatives and selection of building materials and landscape species. Environmental planning usually implies the use of tools to forecast impacts of development decisions including roadway noise computer models, roadway air dispersion models and urban surface runoff computer models. These models first will require a collection of an accurate land use and land cover from satellite imageries. Land use/land cover has become the major

\section{Applications of Remote Sensing in Agriculture}

In India, the agricultural sector sustains the livelihood of around $70 \%$ of the population and contributes to about $35 \%$ of the net national product. The major concern here is to increase food grain production and this requires a multistakeholder approach. We require judicious and optimal management of both land and water resources along with the use of high yielding variety of seed, optimal fertilizer input, pest management, etc.

REMOTE SENSING can provide valuable information for land and water management. Knowledge of food grain production well in advance of harvest enables the country to adopt suitable measures to meet shortages and assist in making policy decisions like the level of buffer stock, imports, fixing of support prices, etc. The first global experiment using satellite remote sensing was to demonstrate the operational capability of Remote Sensing for crop inventory and forecasting, called Large Area Crop Inventory Experiment (LACIE). The goal of LACIE was to develop, test and evaluate a system for predicting wheat production through the use of LANDSAT data for area estimation and weather based empirical regression yield to predict yields.

In India, the Project Crop Acreage and Production Estimation (CAPE) funded by the Ministry of Agriculture was taken up in 1983 in order to provide pre-harvest production estimation of major crops such as rice. Wheat, sorghum, groundnut, cotton, etc. While earlier estimates were carried out using OIR Sensors, of late Microwave SAR Data have been successfully used to provide average estimation. CAPE has two components. Estimating area under the crop and forecasting yield hectare. Identification and discrimination of various crops is based on the subtle spectral signature differences between the crops and the use of digital image processing techniques.

Crop Yield forecasting using remote sensing is more complex than cropped area estimation because of the high variability involved. Crop yield is a function of various parameters like soil, weather, cultivation practice, fertilizer use, irrigation, date of sowing, genotype, pests and diseases, etc. Spectral data over Crop is a 
manifestation of the overall effect of all these factors on its growth. There can be two broad approaches for the use of remote sensing data in yield forecasting. Remote sensing observed data in the form of some kind of vegetation index can be correlated wit crop yield based on actual field data. Thus an empirical relationship can be established.

\section{Application of Remote Sensing and Forestry}

Forests are one of the most valuable ecological resources of global interests. They are the source for many of our essential requirements such as fuel wood, timber, raw material for paper, etc. In addition forests play an important role in balancing $\mathrm{CO}$ supply and exchange. Forests also provide habitat fir numerous animal species. People generally consider the products of forest rather than the forests themselves as useful. This leads to biotic interference of the forests. Thus our forests are continuously disappearing at an alarming rate. A study by FAO shows that the overall forest area is decreasing at the rate of 11.25 Million Hectares per year for the period of 1990-1995. It is now well established that the decrease of forest cover will create a number of serious environmental problems such as soil erosion, floods, global warming, etc. and will seriously affect biodiversity.

Sustainable forest management requires reliable information on the type, density, and extent of forest cover, wood volume, and biomass, forest fires, pest and disease induced losses, encroachment, etc to name a few vital areas. Hence there is a need for timely reliable information and integration of this information in forest management decision making. More emphasis is laid on estimation of changes which requires periodic inventory of forest resources. Remote Sensing provides potential to improve upon the conventional in situ monitoring.

Early methods used to compile information about forests is from interpreting aerial photographs. Panchromatic, B\&W IR, and CIR, photographs were extensively used to find out species and density (crown cover). The photographic characteristics of tone, texture, shape, pattern, etc. are used in interpreting the data. With the advent of space based remote sensing, traditional aerial photographs are being replaced by satellite imagery. Both visual and digital interpretation have been used. The broad areas in forestry for which remote sensing techniques include Mapping./statistics generation of forest cover; Change detection; and Modeling for resource management. 
The first two activities are essentially carried out either by visual interpretation or by digital classification. The third uses remote sensing derived information as one of the inputs along with other databases in a GIS environment and a model to generate the final derived product. All these information data in a GIS environment can generate various scenarios for forest management plans at local, national, or global scales depending on the level of details available.

\section{Application of Remote Sensing and Management of Wetlands}

Satellite remote sensing has proven to a very useful technique for inventorying, mapping and monitoring of wetland ecosystems due to its synoptic coverage, multispectral characters, and repetitive nature. In fact Remote Sensing along with the GIS is the only cost. effective and reliable technology for effective monitoring and management of wetland resources. Studies have also been carried out using orbital remote sensing for monitoring water spread, turbidity/ siltation, aquatic vegetation infestation, and the trophic status of various inland and coastal ecosystems. The scale of mapping for inventory depends on the objectives and the level at which the information is desired.

Mapping and monitoring of wetland ecosystems presupposes the usage of temporal satellite data. The main consideration in the selection of data comprise of the Remote Sensing data of a proper season should be selected to study the wetland parameters. E.g. Pre Monsoon data is more appropriate in finding out about presence or absence of aquatic vegetation. Similarly, for determining turbidity/ siltation both Pre and Post Monsoon data shall be required. The second part is for monitoring purposes; here multi-temporal data should be of the same season and preferably of nearby dates.

A scientific inventory of wetlands in India based on analysis of the Indian Remote Sensing Satellite Data has been carried out. The criteria used to classify and delineate wetlands included: wetland hydrology and wetland vegetation as seen from the IRS-IA/IB LISS-I/II data of False Color Composites.

Conservation and management of wetlands for their sustainable use requires voluminous data on physical, biological, and socio-cultural aspects to understand the structure and functions of the wetland. Remote sensing and GIS can also be used to identify wetland density buffer zones around wetlands, fishery development and host of other wetland watershed related conservational issues. 


\section{Application of Remote Sensing and Coastal Zone Management}

The coastal region is an important part of the Earth's ecosystem with a rich biodiversity. India's coastline, including the shores of islands is about $7,500 \mathrm{~km}$ long. Over $60 \%$ of the world's population live in coastal belt $60 \mathrm{~km}$ wide (which is about $18 \%$ of the land surface) and this number is likely to rise to $75 \%$ by the year 2025 . In India about $20 \%$ of the population is concentrated on the coast. The coastal zone is under increasing pressure due to high rates of human populating growth, industrial development, discharge of municipal sewage, industrial effluents, and solid waste. In addition, the coastal zone is subject to gradual changes brought about by natural processes such as wave erosion, tides, storms, surfs, etc. Therefore it is imperative to manage the coastal development plan of the coastal area.

One of the major requirements for CZM is the availability of up-to-date and accurate information on coastal habitats. Such information was required periodically to study the impact of developmental activities and implementation of laws governing the CZ. Remote sensing technology is the only timely and cost effective means to monitor and map the coastal area at the local, regional, and global scale. Thus coastal resource inventory information through remote sensing technology forms a basis for a comprehensive coastal zone regulation.

In India, coastal wetland, land use and landform, and shoreline change maps have been produced on a $1: 250,000,1: 50,000$, and $1: 25,000$ scale for the whole country using primarily LISS-I, II and III data.

Mangroves are located in difficult terrain and in many places they are almost inaccessible. Therefore remote sensing provides a reliable tool for providing information on mangroves. Mangroves have been mapped for their extent and density at $1: 250,000,1: 50,000$ and 1:25,000 scales using Land sat TM, IRS LISS-II \& III and SPOT Data. For example, density wise classification gives an idea about the condition of the mangrove habitat. Mangroves having $>40 \%$ crown density are termed as dense (closed forests), those having 10-40\% crown density are termed as sparse (open forest); and degraded mangroves have $<10 \%$ crown density. 


\section{Application of Remote Sensing and Marine Fisheries}

Fishery resources from the Indian Exclusive Economic Zone (EEZ) have been estimated at 3.9 million tones per year. Recent estimates by the Fishery Survey of India for the year 2002 also indicate a figure close to this. India contributes to about 40 percent of the fish landing of the Indian Ocean. However when viewed against world production of 90 million tones, India's contribution is about 2 per cent which works out to be less than 2 million tones. Remote Sensing Data provides knowledge of the distribution of high productivity sites where the probability that fish would accumulate for feeding is more. Thus satellite inputs reduce search time for locating fishing sites, thereby also saving fuel required for fishing vessels.

Fisheries forecast systems is well organized using remote sensors to track fish stock. Countries like Japan, USA, and most of the Western Europe use data or information collected from their respective remote satellite tracking stations. For example, Maul et al observed using NOAA AVHRR Thermal IR data, that a high Catch Per Unit Effort (CPUE) was correlated with proximity with surface thermal front of the Gulf Stream. Also the distribution map of fish stock such as tuna has been associated with NOAA AVHRR and Nimbus-7 CZCS. India has adopted the same method for its Potential Zone for Fishing (PZF).

\section{Application of Remote Sensing and Natural Hazards}

For purposes of assessing natural hazards in the context of integrated development planning studies, it is not necessary to have real-time or near real-time remote sensing imagery. What is required is the ability to define areas of potential exposure to natural hazards by identifying their occurrence or conditions under which they are likely to occur and to identify mechanisms to prevent or mitigate the effects of those hazards. This section considers the practical detectability by remote sensing technology of the potential for floods, hurricanes, earthquakes, volcanic eruptions and related hazards, and landslides.

The ability to identify these natural hazards or their potential for occurring depends on the resolution of the image, the acquisition scale of the sensor data, the 
working scale, scenes free of clouds and heavy haze, and adequate textural and tonal or color contrast. The availability of stereo models of the scene being studied can greatly enhance the interpretation.

After a hazard is identified, formulating appropriate mitigation measures and developing response plans may require different remote sensing data sets. This additional remote sensing data needed are most likely to include greater detail of the infrastructure, e.g., roads and facilities.

\section{a. Floods}

Floods are the most common of natural hazards that can affect people, infrastructure, and the natural environment. They can occur in many ways and in many environments. Riverine floods, the most prevalent, are due to heavy, prolonged rainfall, rapid snowmelt in upstream watersheds, or the regular spring thaw. Other floods are caused by extremely heavy rainfall occurring over a short period in relatively flat terrain, the backup of estuaries due to high tides coinciding with storm surges, dam failures, dam overtopping due to landslides into a reservoir, and seiche and wind tide effects in large lakes. Occasionally an eruption on a glacier or snow-covered volcanic peak can cause a flood or a mudflow in which the terrain is radically changed and any agrarian development is totally destroyed, frequently with much loss of life.

It is impossible to define the entire flood potential in a given area. However, given the best remote sensing data for the situation and a competent interpreter, the evidence for potential flood situations can be found or inferred. The most obvious evidence of a major flood potential, outside of historical evidence, is identification of floodplain or flood-prone areas which are generally recognizable on remote sensing imagery. The most valuable application of remote sensing to flood hazard assessments, then, is in the mapping of areas susceptible to flooding.

Synoptic satellite sensor coverage of a planning study area is the practical alternative to aerial photography because of cost and time factors. The application of Landsat MSS imagery to floodplain or flood-prone area delineation has already been demonstrated by comparing pre-flood scenes with scenes obtained at the height of the flood, using Landsat MSS band 7 (near IR) images in a color additive viewer (Deutsch et al., 1973).

\section{b. Hurricanes}

To mitigate the impact of hurricanes, the planner needs to know the frequency of storms of given intensity in the study area, to what extent these storms could 
affect people and structures, and what sub-areas would be most affected such as low-lying coastal, estuarine, and reverie areas threatened by flooding and storm surge.

The determination of past hurricane paths for the region can be derived from remote sensing data from the U.S. National Oceanographic and Atmospheric Administration (NOAA) satellite sensors designed and operated for meteorological purposes. These data are already plotted by meteorological organizations in the U.S.A. and other countries where hurricanes are a threat. For plotting new data, the best sensor is the AVHRR which, with its $2,700 \mathrm{~km}$ swath, makes coverage twice a day, and has appropriate resolution. The red band is useful for defining daytime clouds and vegetation, while the thermal $\mathbb{R}$ band $(10.50 \mathrm{~mm}$ to $11.50 \mathrm{~mm}$ ) is useful for both daytime and nighttime cloud observations.

\section{c. Earthquakes}

The planning of development in earthquake-prone areas is laden with problems. There are large human settlements already located in earthquake/prone areas. As with other geologic hazards, the frequency of occurrence can fall in cycles of decades or centuries. Earthquakes are particularly difficult to predict at this time. Thus, mitigation emphasis is on land use planning (non-intensive uses in most hazardous areas), on building strength and integrity, on response planning, and on incorporating mitigation measures into reconstruction efforts. The main problem is the identification of the earthquake damage-prone zones. While in most areas of great earthquake activity some seismic information is available, it may not be sufficient for planning purposes. Remote sensing techniques and resulting data interpretation can play a role in providing additional information.

\section{d. Volcanic Eruptions and Related Hazards}

Many hazards are associated with the conditions brought about by volcanic activity. Active volcanoes pose hazards which include the immediate release of expelled ash, lava, pyroclastic flows, and/or poisonous hot gases; volcanic earthquakes; and the danger of mudflows and floods resulting from the rapid melting of snow and ice surrounding the vent during eruption. Some secondary hazards may threaten during volcanic activity or during periods of dormancy. These include landslides due to unstable accumulations of tephra, which may be triggered by heavy rains or by earthquakes.

Each volcano has its own particular behavior within a framework of given magmatic and tectonic settings. Prediction of a volcano's behavior is extremely difficult, and the best evidence for the frequency of activity and its severity is the 
recorded history of eruptions. Imminent eruptions are now best recognized by on-site seismic monitoring. Some classifications distinguish between active, inactive, dormant, and extinct volcanoes. But since some of the most catastrophic eruptions have come from "extinct" volcanoes, many volcanologists have abandoned such a classification, settling for a simple distinction between shortterm and long-term periodicity.

Gawarecki et al. (1965) first detected volcanic heat from satellite remote sensing using thermal IR imagery from the high resolution IR radiometer (HRIR). Remote sensing data interpretation can lead to the recognition of past catastrophic events associated with recently active volcanoes (recently in the geologic sense), as in the Andes and the Lesser Antilles (Carribean Sea). This information together with the available historical data can be used as the basis of assessing the risks of an area with potential volcano-related hazards.

\section{e. Landslides}

Landslides, or mass movements of rock and unconsolidated materials such as soil, mud, and volcanic debris, are much more common than is generally perceived by the public. Many are aware of the catastrophic landslides, but few are aware that small slides are of continuous concern to those involved in the design and construction business. These professionals can often exacerbate the problem of land sliding through poor planning, design, or construction practices. Frequently, the engineer and builder are also forced into difficult construction or development situations as a result of ignoring the potential landslide hazard. This can be avoided if there is early recognition of the hazard and there is effective consultation between planners and the construction feam prior to detailed development planning.

The mass movement of bed rock and unconsolidated materials results in different types of slides, magnitudes, and rates of movement. An area with a potential landslide hazard usually has some evidence of previous occurrences, if not some historical record.

The spatial resolution required for the recognition of most large landslide features is about $10 \mathrm{~m}$ (Richards, 1982). However, the recognition depends to a great extent on the ability and experience of the interpreter and is enhanced by the availability of stereoscopic coverage, which can be expensive to acquire. Stereoscopic coverage and the resolution requirements preclude use of most satellite-borne sensor imagery, although large block landslides can be detected on Landsat MSS and TM imagery. 


\section{f. Desertification}

Desertification occurs when an ecosystem experiences a diminution or loss of productivity. This process can have a natural and an anthropic component, which may reinforce each other, creating a synergetic effect. The degree of desertification risk is directly related to certain natural conditions such as climate, topography, natural vegetation, soil, and hydrology, as well as to the intensity and type of anthropic activity in the area. Desertification is among the most serious problems of the region. This trend indicates the increasing need to consider desertification processes in integrated development planning studies. Remote sensing, both space borne and airborne, provides valuable tools for evaluating areas subject to desertification. Film transparencies, photographs, and digital data can be used for the purpose of locating, assessing, and monitoring deterioration of natural conditions in a given area. Information about these conditions can be obtained from direct measurements or inferred from indicators (keys to the recognition of a desertification process).

In order to describe, evaluate, and decide about the type of action to be taken, the following issues should be addressed:

- Location: involves the identification of areas that are currently undergoing desertification and areas expected to be exposed to the forces that can lead to deterioration.

- Assessment: involves the identification and quantification of vegetative cover types, soils, land forms, and land-use change patterns. Vulnerability to change, rate of change, and direction of change in desertification patterns can be studied through this assessment.

- Monitoring: accomplished by detecting and measuring changes in landscape characteristics over a period of time. Comparisons are made between present conditions and previously observed conditions for the purpose of recording the reduction in biological productivity.

Geostationary Operational Environmental Satellite (GOES) data have been used effectively to locate and measure dust plumes; and Seasat SAP imagery has been applied in the delineation of large dune morphology. Land sat MSS and TM and SPOT data have proven to be useful and cost effective for regional assessments. Land sat transparencies of bands 5 and 7 have been used to monitor superficial changes in areas undergoing desertification, and to map present water bodies and former drainage systems. 
Temporal tonal variations on Landsat MSS have been correlated with variations on the field. Movement of sand-dune belts has been detected using Landsat with a multitemporal approach. Albedo changes in arid terrains have been calculated using Landsat digital data: phenomena that tend to lower productivity (increased erosion, loss of vegetation density, deposition of colic sedimentation) also tend to appear brighter on the image. On the contrary, phenomena that tend to increase productivity (increased vegetation, soil moisture), tend to darken the land. In this way, brightness variations can be detected in an area over a period of time. These data can also be calibrated with ground data collected from the areas where change has occurred.

Aerial and space remote sensing provide valuable tools for desertification studies, although, as for any other natural hazard related study, they must be combined with ground-collected data. The use of remote sensing methods should minimize the need for ground data, therefore saving time and resulting quite inexpensive per unit of data. The combination of remotely sensed and ground-collected data can then provide the basis for the assessment.

\section{Geographic Information System (GIS) and Environmental Studies}

In the process of human evolution the issues confronting today are safe guarding the natural environment and maintaining good quality of life. While taking up developmental activities, the assimilative capacities of the environmental components i.e., air, water and land to various pollution are rarely considered. The developmental activities are threatening our environment and in that case the problems of environmental pollution are becoming a heated topic of highrisk.

GIS can play a vital role for analysis and in formulating the quick mitigation plans for high risk environments. GIS is one of the key tools in the environmental data framework for data validation, digital data transfer standards, data retrieval/ dissemination and analysis. It can serve as the ultimate communication of environmental information to the public and policy makers since it is the technical basis for the multimedia approach in environmental decision-making. The evolution of spatial data standards, the Internet, and the next generation of GIS technology allow all types of users to access the environmental information in its proper spatial context. 


\section{Definition of GIS}

GIS is a computer system capable of assembling, storing, manipulating, and displaying geographically referenced information, i.e. data identified according to their locations. Practitioners also regard the total GIS as including operating personnel and the data that go into the system. It is also known as a computerbased tool for mapping and analyzing things that exist and events that happen on earth. GIS technology integrates common database operations such as query and statistical analysis with the unique visualization and geographic analysis benefits offered by maps. Another definition is that GIS is an integrated system of computer hardware, software, and trained personnel linking topographic, demographic, utility, facility, image and other resource data that is geographically referenced.

\section{Brief History of GIS}

GIS is a rapidly growing technological field that incorporates graphical features with tabular data in order to assess environmental systems and problems. What is now the GIS field began around 1960, with the discovery that maps could be programmed using simple code and then stored in a computer allowing for future modification when necessary.

This was a welcome change from the era of hand cartography when maps had to be painstakingly created by hand; even small changes required the creation of a new map. The earliest version of a GIS was known as computer cartography and involved simple line work to represent land features. From that evolved the concept of overlaying different mapped features on top of each other to determine patterns and causes of spatial phenomenon.

\section{Components of GIS}

\section{a. Hardware:}

Hardware comprises the equipment needed to support the many activities of GIS ranging from data collection to data analysis. The central piece of equipment is the workstation, which runs the GIS software and is the attachment point for ancillary equipment. Data collection efforts can also require the use of a digitizer for conversion of hard copy data to digital data and a GPS data logger to collect data in the field. The use of handheld field technology is also becoming an important data collection tool in GIS. With the advent of web-enabled GIS, web servers have also become an important piece of equipment for GIS. 


\section{b. Software}

Different software packages are important for GIS. Central to this is the GIS application package. Such software is essential for creating, editing and analyzing spatial and attribute data, therefore these packages contain a myriad of GIS functions inherent to them. Extensions or add-ons are software that extends the capabilities of the GIS software package. GIS software is the opposite of application software.

Component GIS seeks to build software applications that meet a specific purpose and thus are limited in their spatial analysis capabilities. Utilities are standalone programs that perform a specific function.

\section{c. Data}

Data is the core of any GIS. There are two primary types of data that are used in GIS. A geo-database is a database that is in some way referenced to locations on the earth. Geo-databases are grouped into two different types: vector and raster.

Coupled with this data is usually data known as attribute data. Attribute data generally defined as additional information, which can then be tied to spatial data. Documentation of GIS datasets is known as metadata.

\section{d. People}

Well-trained people knowledgeable in spatial analysis and skilled in using GIS software are essential to the GIS process. There are three factors to the people component: education, career path, and networking. The right education is key; taking the right combination of classes. Selecting the right type of GIS job is important. A person highly skilled in GIS analysis should not seek a job as a GIS developer if they haven't taken the necessary programming classes. Finally, continuous networking with other GIS professionals is essential for the exchange of ideas as well as a support community.

\section{Application of GIS}

Apart from data analysis in laboratories GIS can also help the environmental data analysts in the field, the GIS tool is flexible enough to work in the field to give the exact location of devastation and amount of devastation. Some of the examples in field where GIS is applicable are: 
- Using GIS in the field, an environmental inspector can rapidly map waste storage sites; describe the volume, content, and state of waste containers.

- Retrieve previous inspection records to compare with the existing environmental conditions.

- View environmental data in relation to adjacent geographic features such as waterways, neighborhoods, or other sensitive areas such as high-risk zones for landslides, water pollution etc.

- Integrated with a global positioning receiver, a field crew can use GIS to accurately ground truth satellite imagery in oil spill mapping and its affects on surrounding ecosystem.

The main GIS applicable Areas in Environment are

- Wild Land Analysis

- Emergency Services like Fire Prevention

- Hazard Mitigation and Future planning

- Air pollution \& control

- Disaster Management

- Forest Fires Management

- Managing Natural Resources

- Waste Water Management

- Oil Spills and its remedial actions

- Sea Water - Fresh water interface Studies

- Coal Mine Fires

\section{Application of GIS on Hydrology}

Abilities of remote sensing technology in hydrology are to measure spatial, spectral and temporal information and provide data on the state of the earth's surface. It provides observation of changes in hydrological states, which vary over both time and space that can be used to monitor hydrological changes and conditions.

Sensors used for hydrological applications cover a broad range of electromagnetic spectrum. Both active and passive sensors are used. 
Remote sensing applications in hydrology that are being used today are mainly in:

- Precipitation estimation

- Runoff computations

- Evapotranspiration over land surface

- Water Quality modeling

- Ground water identification and estimation

- Evaluation of soil moisture content

- Hydrological modeling.

\section{GIS in Lake Management}

GIS is used for spatial and temporal assessment which helps in identifying and monitoring the environmental impacts on lakes due to anthropogenic stress. The spatial and temporal changes in the surface of the water bodies are mapped using Survey Of India 1:50,000 scale topographical maps. Integration of thematic layers of water quality and quantity along with socio-economic, land use and population information provide information on the current status and socioeconomic aspects of lakes. It also helps arriving at appropriate restoration and conservation strategies for lake waters. Effective lake restoration technologies include surveying and inventorization of lakes and categorize them, utility, problem, and region wise, to enable impact analysis of ecosystem and evolve suitable restoration works for problem lakes. GIS and Remote Sensing can be an efficient and time saving tool for collecting this information. The next step is to initiate action on Integrated Water Resources Management (IWRM) with specific emphasis on lakes and reservoirs at the basin or sub-basin levels.

\section{Introduction to GPS on Environmental Studies}

Our ancestors had to go to pretty extreme measures to keep from getting lost. They erected monumental landmarks, laboriously drafted detailed maps and learned to read the stars in the night sky. Things are much, much easier today. For less than US $\$ 100$, you can get a pocket-sized gadget that will tell you exactly where you are on Earth at any moment. As long as you have a GPS receiver and a clear view of the sky, you'll never be lost again. When people talk about "a GPS," they usually mean a GPS receiver. The Global Positioning System (GPS) is actually a constellation of 27 Earth-orbiting satellites (24 in 
operation and three extras in case one fails). This was first part of the U.S. military project that developed and implemented this satellite network as a military navigation system, but soon opened it up to everybody else

The Global Positioning System (GPS), is the only fully-functional satellite navigation system. More than two dozen GPS satellites orbit the Earth, transmitting radio signals which allow GPS receivers to determine their location, speed and direction. Since the first experimental satellite was launched in 1978, GPS has become indispensable for navigation around the world and an important tool for mapmaking and land surveying. GPS also provides a precise time reference used in many applications including scientific study of earthquakes, and synchronization of telecommunications networks.

\section{Application of GPS}

A GPS receiver calculates its position by measuring the distance between itself and three or more GPS satellites. Measuring the time delay between transmission and reception of each GPS radio signal gives the distance to each satellite, since the signal travels at a known speed. The signals also carry information about the satellites' location. By determining the position of, and distance to, at least three satellites, the receiver can compute its location using trilateration.

Receivers do not have perfectly accurate clocks, and must track one extra satellite to correct their clock error. In general, GPS receivers are composed of an antenna, tuned to the frequencies transmitted by the satellites, receiver-processors, and a highly-stable clock (often a crystal oscillator). They may also include a display for providing location and speed information to the user.

A receiver is often described by its number of channels: this signifies how many satellites it can monitor simultaneously.

- Helps the environmentalist in field location and navigation

- Used in surveying and mapping of a study area

- GPS helps in coordination of earth satellite communication

- Used a GPS compass in the field

- Used in tracking airborne, terrestrial and marine species

- Used as weather predictions improvements 


\section{References:}

1) Gibson, Paul J.; Power, Clare H.; (2000) Introduction to Environmental Monitoring Techniques from Satellite Data; Introductory Remote Sensing: Digital Image processing and Applications; pp 92 125; Routledge (Taylor and Francis.

2) George Joseph; (2005); Application of Remote Sensing on Earth Resources Management; Fundamentals of Remote Sensing Second Edition; pp 349-387; University Press (India) Limited.

3) George Joseph; (2005); Geographical Information System; Fundamentals of Remote Sensing Second Edition; pp 390-400; University Press (India) Limited.

\section{Electronic Resources:}

a. V. N. Sharma, Jafrullah Mohammed, Srinivas Uppuluri; GIS in Environmental Studies - An overview;

b. http://www.gisdevelopment.net/environment

c. Marshall Brain; Tom harris; How GPS Works; http://wnw.wikipedia.org/GIS

d. http://www.howstuffworks.com/GIS

e. What is GIS: http://www.gislounge.com

f. Remote Sensing in Natural Hazards and Assessment: http://www.oas.org/dsd/publication 